his wife's death in Dorsetshire, he returned to Aberyst. wyth in 1923 and settled at Llanbadarn Fawr. During the succeeding years he walked for miles among the mountains and vales of the Aberystwyth district and his wide knowledge of the flora was partly collected together in "The Flowering Plants and Ferns of Cardiganshire" which he wrote in 1935. His knowledge of bird life was very considerable, and he was instrumental in initiating the movement for the preservation of the Welsh kite in the Towy valley. $\mathrm{He}$ also made a collection of insects which is to be given to the National Museum of Wales, Cardiff.

Since his return to Wales, Dr. Salter has taken a keen interest in his garden, where he has kept records of the flowering periods of some six hundred plants. From the age of seven until the day before his death he kept a natural history diary, which is full of information on birds and plants. The volumes, beautifully written in his neat script, are to be housed in the National Library of Wales.

Dr. Salter was a member of the Society of Friends and $a$ man of the highest principles. He was quiet and reserved in manner, but his knowledge was always freely at the disposal of those who sought it. The fragrance of flowers, the first seasonal appearance of a plant or a bird gave him profound pleasure. No trouble was too great for him if information was desired on a subject with which he was familiar. His tall spare figure will be greatly missed from the Aberystwyth district, for he walked easily, and regularly took a twenty-five mile walk until quite recently.

His passing means that many records will inevit. ably cease to be collected, for he devoted his whole time to work ; it means that many of us will no longer have a fount of wide information generously at our disposal ; and it means also that we shall be denied the privilege of his pleasure when an interesting plant is found. He was a true man of science, a seeker after truth in every sense of the word. It has been a source of deep regret to his friends that the last few months have demanded from him inactivity and suffering.

$\mathrm{He}$ was laid to rest at Llanbadarn Church on August $8 . \mathrm{He}$ is survived by two sons, one of whom is in Canada. As scientific workers we share with them some of the privileges of having known and learned from him. LiLY NEWTON.

\section{Mr. T. Harris}

Mr. T. HARRIS, who has recently died, joined the Research Department, Woolwich, in January 1921 at a time when the importance of the scientific approach to problems of war and defence was beginning to be realized. He became a member of the Ballistics Branch and immediately began experimental work of a fundamental character, to which he brought with enthusiasm his wide knowledge of physics and his skill as an investigator.

The policy in those early days was to build for the future, and it was wisely decided that long-term researches should be undertaken to lay sure foundations for further development. Most of Harris's energies were devoted to such work, and in the course of time he brought to fruition several of these projects about which, because of necessary secrecy, it is impossible to give much detail. It may, however, perhaps be permitted to mention the following items which he either initiated or whose development was directed by him : muzzle vibrations of rifles; temperature of combustion of propellants ; development of methods of photography of bullets in flight, both by single and multiple-spark photography; recoil problems-muzzle and chamber brakes; general internal ballistics of small arms. He was responsible for developments and improvements which have been embodied in weapons in use in the present War.

Harris's methods were essentially sound-careful, meticulous consideration of all aspects of the problem, never rushing to conclusions, and making sure of each step before proceeding further, and it should be said that his mathematical knowledge was considerable and was used with skill to keep theory and experiment in close touch.

The outbreak of war brought heavy demands on his strength and when he and his work were moved from Woolwich in September 1940 he was already a sick man. He never complained and gave unstintedly of his best to ensure the continuation of the investiga tions, but it was clear that the effort was costing him dear. He lived long enough to see things going satisfactorily at the new station, but a bad breakdown in July 1941 kept him away from work for about six months, and, although he struggled back for a few days in January 1942 , it was apparent to all that the end was near. $\mathrm{He}$ inspired respect and affection in all his colleagues, and, to the writer of this notice in particular, he was a close and loyal friend, ungrudging in advice and help at a very difficult time. The country and the national war effort are the poorer by his death.

C. A. C.

\section{Dr. Arnold Berliner}

IN connexion with the obituary notice of Dr. Arnold Berliner (NATURE of September 5, p. 284), Mr. F. I. G. Rawlins writes: In the summer of 1928 , the University of Berlin gave an Abendessen to graduate students attending the Ferienkurs in theoretical physics. Prof. von Laue was host, and I sat next to Arnold Berliner. His conversation was brilliant, over a wide range of topics, and his enthusiasm for straightforward scientific literature unbounded. A few years before he (with Karl Scheel) had produced the monumental "Physikalisches Handwörterbuch", in which I ventured to point out a few (obvious) omissions. He replied at once-"I prepare a new edition, and I promise that there shall be no gaps". Most of the evening, he continued to discuss everything conceivable, but not without betraying some strange - and even violent-likes and dislikes, doubtless the outlet for the "artistic temperament" which filled his whole being. He stood four-square for a culture altogether too broad and too magnanimous ever to suffer complete eclipse.

WE regret to announce the following deaths:

Prof. L. Aschoff, professor of pathological anatomy in the University of Freiburg im Breisgau, aged seventy-five.

Dr. S. G. Barker, O.B.E., scientific adviser to the Indian Jute Mills Association, on August 28, aged fifty-five.

Dr. H. C. Lawrence, formerly of the Imperial Forestry Service, Burma, on August 25, aged sixtyseven.

Mr. P. A. Mytton, O.B.E., chief livestock officer for England and Wales, Ministry of Agriculture, on September 3, aged sixty-one.

Mr. Bernard Neville, formerly physics master at William Ellis School, aged fifty-five. 